Characterization of Hydrogen Complex Formation in III-V Semiconductors

\author{
Final Report \\ Submitted \\ to the \\ U. S. Department of Energy \\ Office of Basic Energy Sciences
}

by

Michael D. Williams, Ph. D.

Center of Excellence in Microelectronics and Photonics

Department of Physics

Clark Atlanta University

Atlanta, GA 30314

September 28, 2006 


\section{Executive Summary}

Atomic hydrogen has been found to react with some impurity species in semiconductors. Hydrogenation is a methodology for the introduction of atomic hydrogen into the semiconductor for the express purpose of forming complexes within the material. The effect is to suppress the carrier concentration in the region of exposure. This phenomenon can be exploited to form semi-insulating regions in fabricated devices after appropriate masking and to improve the electron transport characteristics by reducing the deep level trap density. It is possible now to define novel device structures without the use of etchants or ion implantation. Efforts to develop hydrogenation as an isolation technique for $\mathrm{AlGaAs}$ and Si based devices failed to demonstrate its commercial viability. This was due in large measure to the low activation energies of the formed complexes. Recent studies of dopant passivation in long wavelength $(0.98-1.55 \mu \mathrm{m})$ materials suggests that for the appropriate choice of dopants much higher activation energies can be obtained.

This effort studied the formation of these complexes in InP, The materials cited is extensively used in optoelectronics, i.e., lasers, modulators and detectors. The experimental techniques were general to the extent that the results can be applied to other areas such as sensor technology, photovoltaics and to other material systems. The activation energies for the complexes have been determined and are being reported in the scientific literature. The hydrogenation process has been shown by us to have a profound effect on the electronic structure of the materials and was thoroughly investigated. The information obtained will be useful in assessing the long term reliability of device structures fabricated using this phenomenon and in determining new device functionalities.

\subsection{Introduction}

The study of the kinetics and dynamics of impurity carrier distribution is an important area of concern for optoelectronic materials based on III-V compound semiconductors. Photonic integrated circuits (PIC's) are particularly sensitive, in this regard. For example, the band gap renormalization resulting from the redistribution of active carriers with current injection in laser/modulator structures affects macroscopic parameters like chirp, bandwidth and frequency response[1]. This phenomenon is of critical importance in device design as the packing density and complexity of device structures increases on the chip. 
A typical PIC structure for the telecommunications industry contains a lasermodulator pair and a detector for monitoring and feedback control. The laser is driven by current injection across the active region in a forward-biased configuration and must be electrically isolated from the RF driven modulator. The detector, which typically has the same material makeup as the laser, is operated under reverse bias. The close proximity of these separate components requires a high degree of isolation to prevent crosstalk or interference effects, as described above. A $40 \mu \mathrm{m}$ spacing between components requires $\geq 10 \mathrm{k} \Omega$ isolation. This isolation is usually accomplished with either ion implantation or etch-and-regrowth with semi-insulating material. The accepted method, in general, for isolation is ion implantation. An implanter has a capital cost of several millions of dollars and requires highly skilled operators. Etch-and-regrowth has also gained some acceptance among manufacturers of PIC's. This latter approach uses chemical or dry etching techniques to form a trench around the selected structures. Semiinsulating material is subsequently grown in these trenches for isolation and to preserve the optical waveguide characteristics. The regrowth aspect of this approach, of necessity, also dictates the availability of highly skilled operators. A further logistical complication exists in that the epitaxial growth apparatus used to grow the PIC is also that typically used for regrowth. In both of these approaches the isolation technique adds an additional un-recoverable yield loss factor to the production cycle. A simple and effective alternative process that can be exploited is hydrogenation.

Hydrogenation is a methodology that introduces atomic hydrogen into a crystalline semiconductor through a controllable and well defined process. The typical process and the one utilized here involves exposure of the semiconductor to a hydrogen plasma. Atomic hydrogen reacts with some dopant species in semiconductors to form complexes and passivates deep level trap states [2-3]. The former effect is to suppress the carrier concentration in the exposed region. The latter results in a significant improvement in the carrier mobility and scattering length. It is intuitively obvious that this phenomenon can be exploited to form semi-insulating regions in fabricated device structures after appropriate masking. An example of this is the gain guided laser described by Holynak et al. at the University of Illinois in 1987 in which the current guiding was provided by resistive hydrogenated regions [4]. Hydrogenation has a clear advantage over ion implantation in this application in that there are no extrinsic defects close to the active region to act as nonradiative recombination centers [5]. This approach has generally not been considered because of the low activation energies $(\sim 1 \mathrm{eV})$ associated with the 
formation of the complexes [6]. Typical processing temperatures would reverse the effect, under this constraint, but it also gives the advantage that errors in this processing step are fully recoverable. Hydrogenation thus makes chip isolation a high yield step that can be applied near the end of the production cycle where temperature cycling is not a factor. The simplicity of the process with regard to use and economics facilitates its use, at the very least, for proof of principle device structures. Recent results [7] suggested that higher activation energies are to be had for some systems thus making the technique an acceptable alternative to the traditional isolation techniques.

Most work to date in the III-V's has been concentrated in GaAs and AlGaAs, InGaAs, InP, and more recently the nitrides [8-11]. The effect of hydrogenation on As, P, and As$\mathrm{P}$ based quaternaries is a virtually untouched area. Recent work indicates that the activation energy is directly proportional to the strength of the H-column V element bond [11]. Preliminary work by us. [7] also showed significant differences in the reaction kinetics with the epitaxial growth technique used and for dopants other than $\mathrm{Zn}$ in p-type InP. The materials cited above are extensively used in optoelectronics, i.e., lasers, modulators and detectors. The information derived can be applied to other areas such as sensor technology and photovoltaics.

\subsection{Objectives and Relevance to the Office of Basic Energy Sciences}

This work was concerned with obtaining a fundamental understanding of the nature

of the chemical reaction obtained by passivating dopant impurities and deep level traps in semiconductors with atomic hydrogen. Three objectives were associated with this effort. The first was to study the reaction kinetics of the hydrogen complex formation in III-V semiconductors. This was accomplished by determining the activation energies for the reactions. The second was to determine the effect of hydrogenation on the electronic structure of the host material. The final objective was to mentor and train students in areas of technological importance as well as in basic research.

This project was relevant to the mandate of the Solid State Physics Program under the Division of Materials Sciences in the Department of Energy (DOE). The systems studied are semiconducting materials that are of technological relevance to microelectronics and optoelectronics. A primary benefit was the prospect of obtaining a fundamental understanding of the reaction kinetics of atomic hydrogen with the dopant species. The knowledge obtained can be used to evaluate the hydrogen passivation of these impurity 
defects as a viable process for device prototyping or as an environmentally friendly and economical isolation technique for device production. An equal benefit to the Office of Basic Energy Sciences was the opportunity to play a critical role in establishing Clark Atlanta University (CAU) as a leading institution in the retention of minorities in the sciences by giving the targeted population access to leading edge science and state-ofthe-art facilities.

\subsection{Experimental Approach}

The activation energy for hydrogenation in a particular dopant-III-V semiconductor matrix was initially determined by measuring the resistances for a set of hydrogenated samples of the material where each sample underwent a particular annealing temperature. The annealing temperatures were progressively increased until the resistance returned to that of the pre-hydrogenated matrix. Figure 1 shows a schematic for the previous sample configuration. It was derived from two laser elements of a multi-wavelength array [12] and required considerable lithographic processing. The back-to-back Schottky diode resistance was experimentally a simple measurement and yields an unambiguous result. The reader should note that one of the junctions is reverse biased and the other is forward biased in this arrangement. The particular material system shown here is $\mathrm{Zn}$ doped InP (100) which has been measured previously by Williams et al. [7] and others [6]. It was described here originally as the template for the process that was to be used in this study. The p-InP layer is epitaxially grown on top of an n-type substrate and capped with 2500 $\AA$ of $\mathrm{p}$-InGaAs for ohmic contact. $2500 \AA$ A thick Au/Zn contacts are applied by evaporation after the patterned wafer is wet etched to form mesas. Prior to hydrogenation, a diffusion barrier consisting of $2500 \AA$ of $\mathrm{SiO}_{2}$ is deposited on top of the $\mathrm{Au} / \mathrm{Zn}$ contacts to prevent passivation of the underlying material during the atomic hydrogen exposure. In the region of exposure, a thin $(\sim 100 \AA)$ hydrogen permeable layer of $\mathrm{SiN}_{\mathrm{X}}$ is deposited by plasma enhanced chemical vapor deposition. This latter layer protects the InP layer from degradation and P loss during the exposure [13]. Alternatives to $\mathrm{SiN}_{\mathrm{X}}$ are available. $\mathrm{SiO}_{2}$ for example would work equally well and could be deposited by simple thermal evaporation. The patterned sample wafer was hydrogenated by exposure to a hydrogen plasma generated by an RF source under vacuum conditions. The thickness of the p-InP:Zn layer was chosen to be thinner than the diffusion length of hydrogen in InP. The wafer was subsequently cleaved up into individual samples and annealed in forming gas in a rapid thermal annealing oven. The $\mathrm{SiO}_{2}$ and $\mathrm{SiN}_{\mathrm{X}}$ layers were then removed by a brief immersion in dilute HF acid. The resistance measurements 
were taken between adjacent mesas as described above on an electronic probe station using a suitable parametric analyzer equipped with current and voltage sources. 


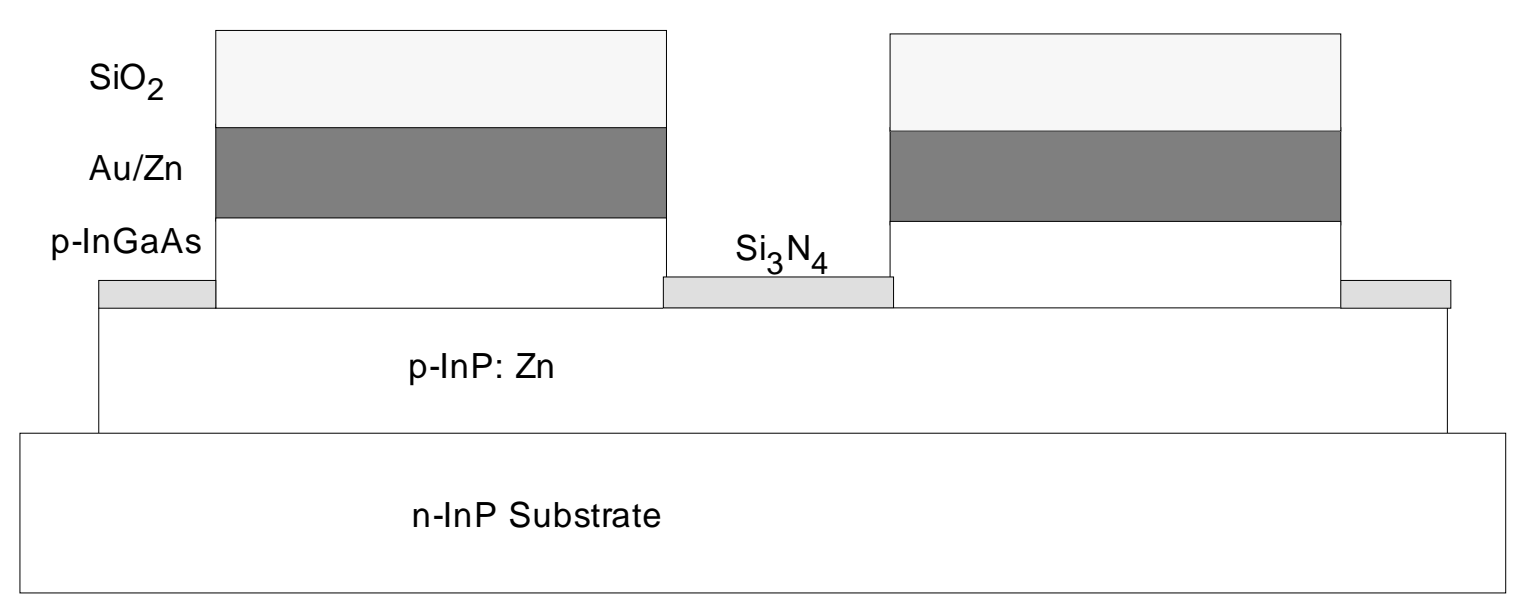

Figure 1. Schematic of Test Structure for Activation Energy Analysis

Two significant results were obtained from this approach. The first was that the Bedoped InP samples had back-to-back Schottky resistances that were several orders of magnitude higher than for the $\mathrm{Zn}$-doped material. The value for the $400 \mathrm{~K}$ anneal, e. g., was $60 \mathrm{M} \Omega$ for the Be-doped InP while the corresponding resistance for the $\mathrm{Zn}$-doped material was $846 \Omega$. The second feature was that the activation energy for the dissociation of the $\mathrm{H}-\mathrm{Be}$ complex was significantly higher at $2.57 \mathrm{eV}$ than that for the $\mathrm{H}$ $\mathrm{Zn}$ complex.at $1.99 \mathrm{eV}$. The reader should note that this value is $77 \%$ of the dissociation energy of the InP molecule itself $\left(E_{A}\right.$ is $\left.3.34 \mathrm{eV}\right)$. We found that the value for the $\mathrm{H}-\mathrm{Zn}$ complex is much higher than the typical value of $1.0 \mathrm{eV}$ found in the literature. We concluded that the higher activation energy values were due to unreacted hydrogen trapped in the material due to the forward-biased contact in the back-to-back Schottky configuration. We consequently abandoned this approach and adopted the method of S. J. Pearton, et al $[6,10]$ whereby the activation energy is determined from the variation of the dissociation frequency of the $\mathrm{H}$-dopant complex with sample temperature. The dissociation frequency is determined from the diffusion analysis of the active carrier fraction of the annealed samples. The activation energies for the $\mathrm{Cd}$ and $\mathrm{Zn}$-doped $\mathrm{InP}$ samples taken with this latter approach are consistent with those found in the literature and we will continue to use this approach in the subsequent evaluations. The study of the As and P-base materials will be extended to include the III-V nitrides.

A diffusion analysis was done by depth profiling of the active carriers and hydrogen atomic mass in bulk hydrogenated material. The active carrier profile was measured by electrochemical capacitance-voltage profiling. We showed that the carrier concentration 
of Be-doped InP (100) can be compensated by more than four orders of magnitude by diffusion of atomic hydrogen generated by an electron cyclotron resonance plasma source [7]. We opted to use a RF plasma source due to its higher efficiency for producing atomic hydrogen. The solubility limit for Be in InP is on the order of $2 \times 1018 \mathrm{~cm}^{-3}$. Chemical beam epitaxy allows doping to $3 \times 10^{19} \mathrm{~cm}^{-3}$ with an effective carrier density of $4 \times 10^{18} \mathrm{~cm}^{-3}$. C-V depth profiling shows effective compensation of the carriers within the first $0.4 \mu \mathrm{m}$ from the surface. Be has a larger electronegativity than that of $\mathrm{Zn}$ and its greater degree of compensation may be explained by its higher affinity for $\mathrm{H}^{+}$.

The effect of the hydrogenation on the valence band structure of the material was ascertained with ultraviolet photoemission spectroscopy (UPS) as a function of in situ reverse biased vacuum anneals. The $\mathrm{He} \mathrm{I}(21.2 \mathrm{eV}, 3 \mathrm{meV}$ linewidth) line from a differentially pumped VSW UV-10 discharge lamp was used as the optical excitation source. Transmission filters and the He discharge pressure were used to discriminate between the He I and $\mathrm{He}$ II (40.8 eV, $17 \mathrm{meV}$ linewidth) spectral lines present in the discharge. The 4-5 A escape length of the photoemitted electrons excited by the He I line provides a surface sensitive measurement of the joint density of states of the valence band (VB) of this material. The vacuum level achievable in the analysis chamber during the UPS measurements is 1-2 x 10 -9 Torr. The angle integrated kinetic energy distribution of the electrons was measured with a PHI 15-255 GAR double pass cylindrical mirror analyzer operated in the retarded mode with an instrumental resolution of $\pm 0.053 \mathrm{eV}$. The samples will be annealed under UHV conditions using radiative heating from a resistive filament mounted behind the wafer block. The reverse biasing of the sample during the anneal was accomplished by forming a capacitive circuit between the sample surface and the flat inner surface of the grounded sample transfer receptacle with a gap of about $1 \mathrm{~cm}$. The samples were biased positively with respect to ground during the sample anneal and its subsequent cooling back to room temperature (RT). All UPS spectra were taken at RT with a negative sample bias to ensure that the sample's work function determines the low energy threshold of the photoemission electron distribution curves (EDCs). No distortion of spectral features was noted as a result of the sample bias below $-5 \mathrm{~V}$ on this analysis system.

\subsection{Accomplishments: 1997 to 2006}


All capital equipment specified in the grant proposal for each year has been purchased and installed.

The processing station for hydrogenation was assembled from the capital equipment items purchased and from instrumentation already on hand in the Center and was operational in the first year. One undergraduate student, Kennan Goodman,assisted in the assembly of the station.

Samples were procured by purchase from TLC Precision Wafer Manufacturing, a small disadvantaged minority business, and via collaboration with Prof. Theda Daniels-Race of Duke University (now at Louisiana State University). Daniels-Race is supported by OBES and has been involved in collaborative efforts with the Center to characterize the epitaxial processes associated with the growth of InGaAs.

The Center negotiated an agreement with TLC whereby staff would be sent on an as needed basis to assist in the calibration and maintenance of the MBE systems and the capacitance-voltage $(\mathrm{C}-\mathrm{V})$ etch profiler.

The Polaron C-V etch profiler and a higher resolution (and lower operating costs) Amray 1600 scanning electron microscope (SEM) were donated to the Center by Lucent Technologies-Bell Laboratories in the first year. The Amray microscope replaced the Center's lower resolution Philip's 501B microscope. The Philip's 501B SEM has been set up for use by the general research population at the University. The Center is currently negotiating the donation of a Hitachi 800 SEM from Material Analytical Services to upgrade our SEM capabilities. This instrument has, in addition to its imaging capabilities, energy dispersive X-ray analysis and digital imaging. The Amray has been transferred to the Biology Department here at Clark Atlanta.

We made an early attempt in the second year to establish a correlation between the deactivation energies for various hydrogen-column $\mathrm{V}$ complexes detailed in the literature and the electronegativity of the p-type impurity dopant. Work by Jalil et al [11] indicated that the activation energy is directly proportional to the strength of the $\mathrm{H}$ column V element bond. The model considered was that the lower the electronegativity of the dopant the easier it would be for the hydrogen atom to insert itself into the tetragonal bonding configuration and form the complex with the anion. With decreasing 
ionicity, i. e., decreasing electronegativity, the complex could completely decouple from the parent tetragonal configuration yielding a maximum in the deactivation energy. Unfortunately, there was not enough consistent data tabulated in the literature to draw any meaningful conclusions. Our current approach will give a self-consistent set of data upon which one can examine this issue. The results, to date, suggest that higher deactivation energies are to be had for particular dopant-III-V systems and we are engaged in the identification of the mechanisms involved.

The hydrogen-dopant activation energy is determined by measuring the resulting variation in the carrier concentration as measured by the $\mathrm{C}-\mathrm{V}$ etch profiler. This methodology is different from the one originally proposed where contacts were to be patterned on the various samples and I-V measurements made to determine changes in resistance. The method used with the $\mathrm{C}-\mathrm{V}$ profiler is simpler and eliminates the effect of hydrogen retrapping and will be used exclusively. The activation energies for the $\mathrm{Zn}-\mathrm{H}$ and $\mathrm{Cd}-\mathrm{H}$ complexes were found to be $1.14 \pm 0.45 \mathrm{eV}$ and $1.33 \pm 0.20 \mathrm{eV}$, respectively. This is consistent with the results found in the literature and we were thus encouraged to proceed with the $\mathrm{Be}$ and $\mathrm{Mg}$ dopant systems. We are almost at a point now, with respect to the data on hand, to evaluate the correlation (and its consistency with existing theoretical treatments) for InP. Our current approach will give a self-consistent set of data upon which one can examine this issue.

A potentially new process for producing cold electrons has emerged from this effort. Our UPS results showed a strong influence on work function and electronic structure that may impact cold cathode performance. By judicious positioning of atomic hydrogen in the semiconductor, the amount of energy necessary to transport electrons from the material into its surrounding environment is dramatically reduced. The electrons produced are cold in the sense that they have a very narrow distribution of energies, which makes them extremely useful for scientific and commercial applications. One of the more obvious commercial applications of such a cold cathode source is to flat panel display technology as this process offers significant cost advantages over present LED, LCD and plasma technologies.

The results of the UPS study of the hydrogenated InP:Zn study are shown below in Figure 2. The figure displays the valence band structure of the material for room temperature (RT) and reverse-biased anneals at $100^{\circ} \mathrm{C}$ and $200^{\circ} \mathrm{C}$. Two effects are immediately noticeable. The first is that the maximum kinetic energy edge, valence band 
maximum, of the spectra remains fixed while there is a significant change in the low kinetic energy edges. This resultant change in width of the band is a clear indication of a dramatic change in work function of the material. The second observation is that the X6L6 feature associated with the crystalline state of the material is essentially quenced at $\mathrm{RT}$ is evident at the $100^{\circ} \mathrm{C}$ anneal and is diminished with the $200^{\circ} \mathrm{C}$ anneal. This diminishing of the peak with the $200^{\circ} \mathrm{C}$ anneal is also accompanied by a narrowing of the band. Given the $5 \AA$ probing depth of the technique, we surmise that the initial anneal depletes the near surface region of hydrogen and returns the material to its native state. The subsequent $200^{\circ} \mathrm{C}$ anneal diffuses hydrogen from the bulk where it is retrapped in the surface region. To our knowledge this is the first view of the retrapping phenomena using an electronic structure analysis. It also shows that a simple work function analysis can be used to determine the state of hydrogenation. A presentation of these results was given at the $51^{\text {st }}$ International Symposium of the American Vacuum Society in Anaheim, Ca in November 2004. A manuscript describing this work has been submitted for publication in Applied Surface Science.

A second photoemission study of the system hydrogenated with a bare InP surface was also performed and is shown in Figure 3. An analysis of the work function and electron affinity variation with temperature processing (see Figure 4) shows that a state of negative electron affinity is readily achievable for InP passivated with InGaAs prior to hydrogenation. The depletion of the hydrogen from the surface region with the low temperature anneal forms a very thin dipole layer ( $\mathrm{p}$-InP) on top of an underlying semiinsulating hydrogenated p-InP region. Any free electrons introduced into the outmost doped layer will tunnel or be injected into the vacuum under appropriate biasing conditions. InP hydrogenated without the benefit of a protective passivation layer (surface damage etched away) exhibits a weak display negative electron affinity and this is attributed to the surface roughness impeding the establishment of a uniform surface dipole layer. The detailed analysis of this system and the production of the negative electron affinity state will be presented in the technical literature.

We have also completed a photoemission study of AIN to ascertain the effects of temperature on the work function variation of the material. This was a collaborative work with Prof. David. E. Aspnes at North Carolina State Univ. 


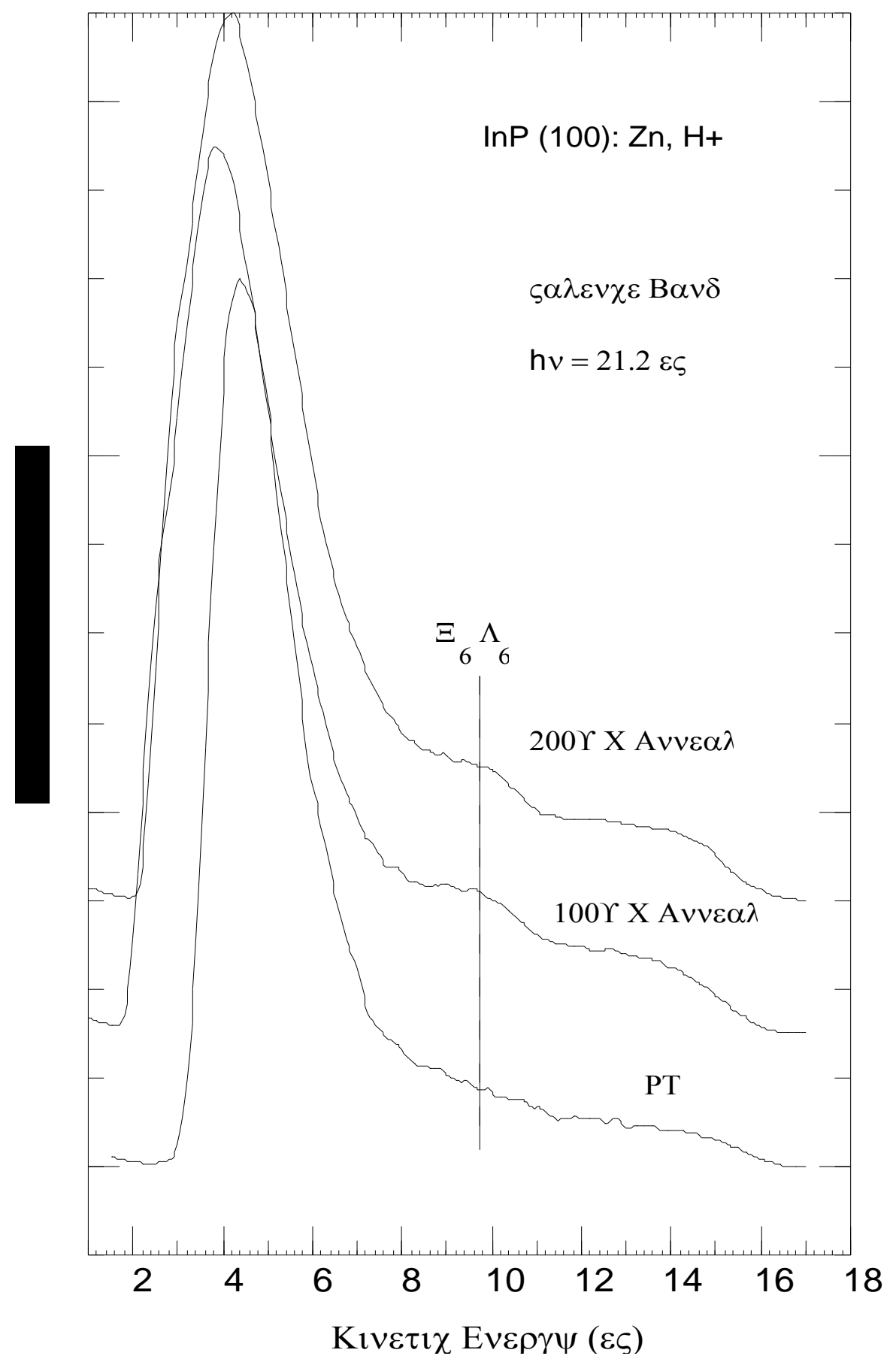

Figure 2 


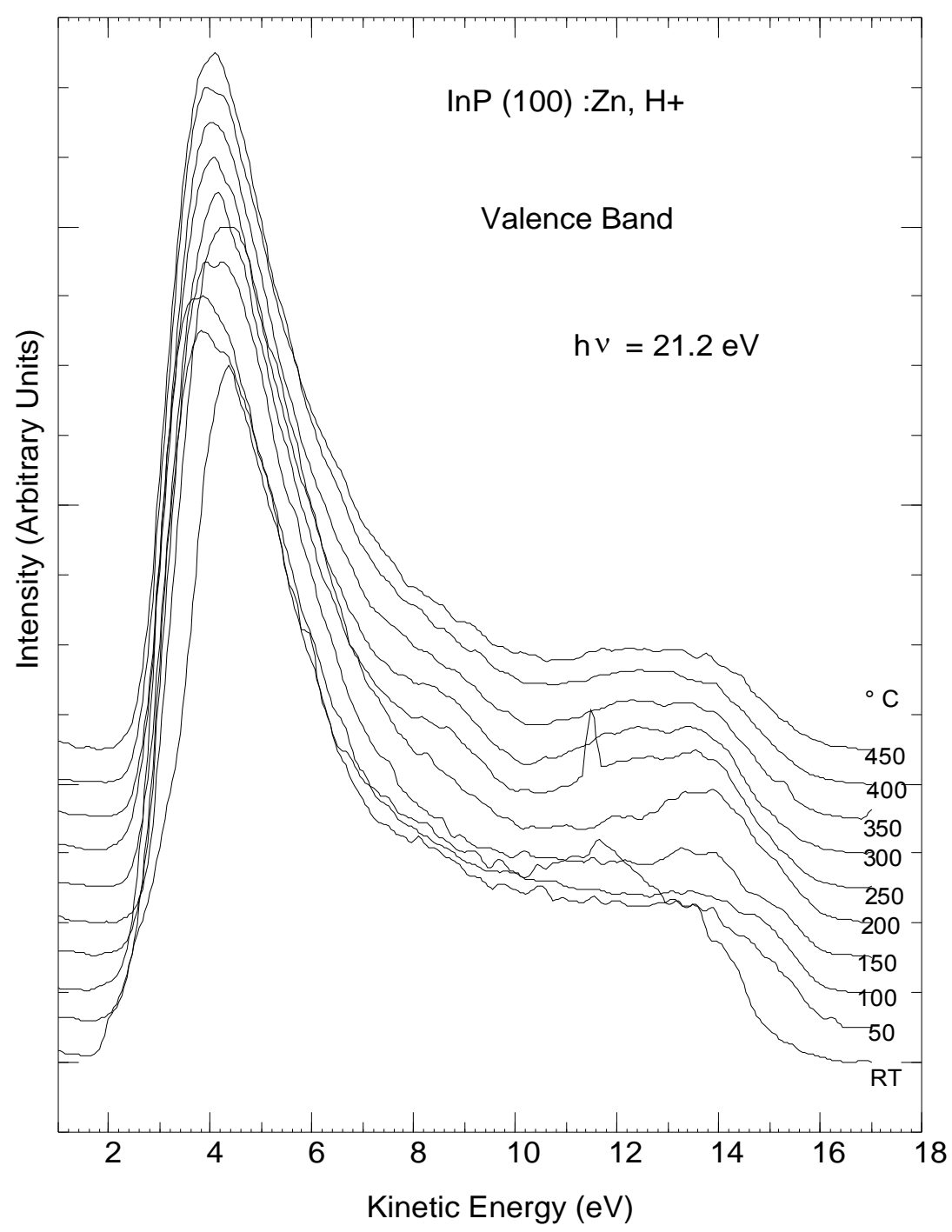

Figure 3 
InP (100): $\mathrm{Zn}, \mathrm{H}+$
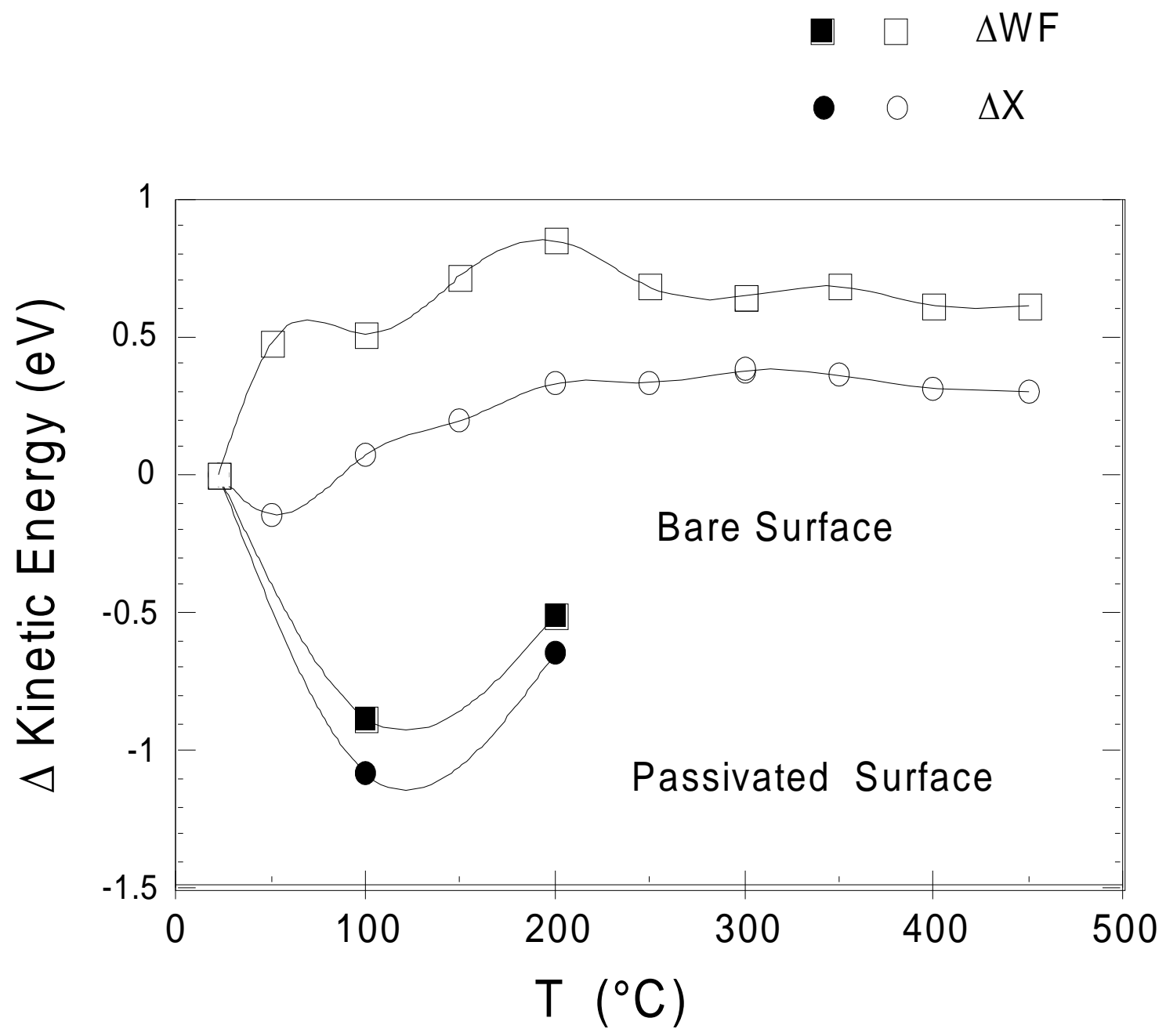

Figure 4 
Ion implanted $\mathrm{Mg}$ and $\mathrm{Be}$ doped InP (100) samples were procured during the last renewal period The samples were passivated prior to hydrogenation at Georgia Tech through a collaboration with Mr. Walter Henderson in their Microelectronics Research Center. Mr. Henderson was the first MS student from this project. Reverse bias anneals were used for the Arrhenius determination of the activation energies. The passivation layer was chemically removed prior to the annealing step. This ensured that the decomposition of the $\mathrm{H}$-dopant complex during annealing cycle is a first-order reaction process. The $\mathrm{C}-\mathrm{V}$ depth profile analysis of the annealed samples then gave the requisite variation of the dissociation frequency for the complexes with heating for the activation energy determination. Secondary ion mass spectrometry analysis of the InP:Zn system has been performed and will be compared to the previous $\mathrm{C}-\mathrm{V}$ depth analysis.

\subsection{Impact}

Five undergraduates have been involved with the project, to date. Mr. Kennan Goodman, as mentioned, assisted in the assembly of the hydrogenation station. The second, Ms. Ade Abatan, was a Chemical Engineering student. During her junior year (1999), she became familiar with the operation of the RF source and vacuum apparatus. She was also intimately involved in searching the literature for the attempt to corroborate the "ionicity" model detailed above. Mr. Goodman finished his matriculation at Clark Atlanta with a B.S. and M. S. degrees in physics (1999) and is currently working for IBM in North Carolina. Ms. Abatan rotated to a project in chemical engineering during her senior year of undergraduate studies and is currently in graduate school in chemical engineering. Two faculty members from the Physics Dept. and one from the Chemistry have also participated in this project.

Mr. Walter Henderson, completed his M. S. requirements in December 2000 and graduated in May 2001. His thesis work on this project is entitled "Characterization of Dopant Passivation by Atomic Hydrogen in Indium Phospide (100)". Two faculty members from the Physics Dept. and one from the Chemistry have also participated in this project.

The second M. S. student Ms. Shala Mance joined the effort during spring of 2000. Ms. Mance designed and fabricated a miniature photoluminescence system, as described above, for sample characterization. Ms. Mance and the PI attended the $2001 \mathrm{March}$ Meeting of the American Physical Society in Seattle, Washington. She has a strong interest and commitment to secondary and undergraduate science education. This interest 
was solidified by her attendance at a meeting of the American Association of Physics Teachers. Ms. Mance completed her non-thesis M. S. requirements in December 2001. Her seminar presentation to the physics department of Clark Atlanta University on the non-thesis project was entitled, "Small Spot Photoluminescence for Nanostructure Characterization of III-V Semiconductors".. She is now a lecturer at Southern Polytechnic University in the metropolitan Atlanta area.

The third undergraduate student, Ms. Shevon Johnson, has used our expertise in surface characterization and etching to expand upon a summer NSF-REU project with Cornell University to produce self-ordered anodic porous aluminum to develop a bonelike surface for the study of prostate cancer metastasis. Ms. Johnson graduated in May 2002 with a B. S. in Physics. She obtained a MS. in biomedical engineering from Georgia Tech and is a patent examiner at the US Patents and Trademarks Office in Washington, DC.

Two students, Ms. Sharah Yasharahla (formerly know as Rashidah Campbell) and Ms. Ngoneh Jallow, have mastered the operation of the hydrogenation apparatus. Ms. Jallow was the fourth undergraduate Physics student and expressed an interest in continuing on for the MS degree in Physics here at Clark Atlanta and is currently enrolled as a BS/MS candidate. Ms. Shana Williams, a graduate chemistry student, was trained in the use of photoemission spectroscopy for analysis of the electronic structure. She has since transferred to the Ph.D. program in Forensic Science at Louisiana State University. Ms. Yasharahla completed the requirements of the academic program in Physics for the MS degree in December 2004 and has been accepted into the Ph.D. program in Physics at the University of Georgia in Athens, Ga. The fifth undergraduate is Mr. Tolu Akinduro. He is in Clark Atlanta's Dual Degree Engineering Program and will be graduating in May 2007 with a BS in Physics and Electrical Engineering.

Eight minority students have been trained in materials growth and characterization under the support of this grant to date.

In addition to the usual attendance to the March Meetings of APS and the Annual Symposia of the American Vacuum Society, the grant has allowed the PI to attend the ORNL Workshop for Nanophase Materials Sciences (October 2001). At this meeting, I was asked by the APS Division of Materials Physics to organize and chair a focused session on "Defects in Semiconductor" for the 2003 March Meeting of APS. This focus 
session did not make the program slate. In lieu of this, I was asked and consented to serve on the Nominating Committee for the Division. I also attended the 2002 APS March Meeting in Indianapolis, IN where I chaired an invited session sponsored by the APS Committee on Minorities in Physics. My stature in the scientific community has been steadily improving due, in my opinion, from the continued support of DOE-Science. I have participated lately in several joint proposals, unfortunately unsuccessful to date, with local institutions to establish NSF nanotechnology centers (Georgia State, Duke University, Georgia Tech, New Jersey Institiute of Technology). I have been chair of the APS Committee on Minorities in Physics. I am now serving on the Chapter, Groups, and Divisions Committee of the American Vacuum Society.

\subsection{Technical Milestones}

Table 1 shows a listing of technical activities accomplished.

\begin{tabular}{|c|c|c|c|c|}
\hline$\underline{\mathrm{Yr}}$ & $\begin{array}{l}\text { MBE } \\
\text { Growth }\end{array}$ & $\begin{array}{l}\text { Sample } \\
\text { Procurement }\end{array}$ & Processing & $\begin{array}{l}\text { Sample } \\
\text { Analysis }\end{array}$ \\
\hline 1 & MBE Installed & p-InP: Zn, Be & \multicolumn{2}{|c|}{ RF Source Installed } \\
\hline \multirow[t]{2}{*}{2} & MBE Repaired & p-InP: Cd & bulk & Diffusion Length (CV) \\
\hline & & & \multicolumn{2}{|c|}{ Thermal Annealer Fabricated } \\
\hline \multirow[t]{2}{*}{3} & \multirow[t]{2}{*}{ GaAs Growth } & & bulk & Diffusion Length (CV) \\
\hline & & & bulk & Diffusion Length (SIMS) \\
\hline 4 & InGaAs & p-InP:Zn & bulk & Diffusion Length (CV) \\
\hline \multirow[t]{3}{*}{5} & InGaAs & p-InP: Zn, & \multirow[b]{3}{*}{ bulk } & Activation Energy \\
\hline & InGaAs & p-InP: Cd, & & Activation Energy \\
\hline & & & & Diffusion Length \\
\hline \multirow[t]{3}{*}{6} & \multicolumn{3}{|c|}{ p-InP:Be, Mg } & Activation Energy \\
\hline & & \multicolumn{2}{|l|}{ p-InP:Zn } & Electronic Structure (UPS) \\
\hline & & \multicolumn{2}{|l|}{$\mathrm{AlN}$} & Electronic Structure (UPS \\
\hline
\end{tabular}




\subsection{Qualifications of Principal Investigator}

Michael D. Williams is an associate professor in the Department of Physics and director of the Center for Microelectronics and Photonics. His research interest is to understand and exploit the effects of strain and growth morphology at the interfaces and surfaces on the electronic valence band structure and morphology of epitaxially grown, thin film, compound semiconductor structures. Dr. Williams was formerly a member of technical staff in the Optoelectronics Research Department at AT\&T Bell Laboratories' Holmdel, NJ facility. He joined AT\&T in 1987 after completing an appointment as a visiting scientist (post-doctoral fellowship) at IBM's Almaden Research Center in San

Jose, Calif. He has a B. S. degree from Morehouse College (Atlanta, Ga), a B. S. degree in Nuclear Engineering from the Georgia Institute of Technology (Atlanta, Ga), and M. $\mathrm{S}$. and $\mathrm{Ph}$. D. degrees in Physics from the Leland Stanford, Jr. University (Stanford, Calif.). He was also a recruiter for AT\&T's Special Programs (summer internships, graduate fellowships, and grants) that are targeted for increasing the number of minorities and women in the sciences. Dr. Williams joined the faculty of CAU in 1994. He is a natural role model for the students and has the primary responsibility of developing a center for microelectronics and photonics. Dr. Williams is a member of the American Physical Society, the American Vacuum Society, the National Society of Black Physicists, Sigma Pi Sigma, Beta Kappa Chi, and Sigma Xi. He has over 20 years of experience in the surface physics of III-V compound semiconductors.

\subsection{Facilities and Resources}

\subsection{Instrumentation}

AT\&T Bell Laboratories (now Lucent Technologies - Bell Laboratories) donated a considerable amount of capital equipment to facilitate the development of this work. The relevant items of interest for this project are a Riber R \& D solid source MBE reactor for the growth of III-V (arsenides) material for depth profiling, a secondary ion mass spectrometer (60 ̊ depth resolution with Atomika $\mathrm{O}_{2}{ }^{+}$source), a custom Perkin Elmer surface analysis system for auger and photoemission spectroscopies equipped with a VSW UV-10 ultraviolet discharge lamp and a VSW twin anode (Y and Mg) x-ray source, a Philips 501B scanning electron microscope (1000 Å resolution), an Amray 1600 scanning electron microscope ( $40 \AA$ A resolution), a Rucker Koll model 667 electronic probe station, an International Plasma Corp. Series 2000 plasma processing reactor for 
plasma cleaning and etching,, a Balston 75-32NA hydrogen generator, and miscellaneous vacuum hardware.

CAU provided a Polycold Systems model PFC 100 cryogenic heat exchanger $(\$ 24,600)$ and a Neslab HX 300A recirculating chiller $(\$ 8,500)$ to support the MBE reactor, a Terra Universal Series 100 nitrogen glove box $(\$ 3,300)$ for MBE sample preparation, a Balston 75-92 ultra high purity nitrogen generator (\$6000) for environmental control and purging, a Barnstead E-pure DI water still $(\$ 3,300)$ for processing, and laboratory space with facilities support. The Balston 75-92 nitrogen generator has been replaced by funds from this grant.

Four basic capital equipment items were necessary to facilitate the outlined program. These were a plasma source for hydrogenation, a turbomolecular pump to evacuate the hydrogenation chamber, and a electrochemical capacitance-voltage (CV) etch profiler to ascertain the diffusion characteristics of the active carriers. The first two items have were purchased under the grant and are operational. The third item is The Polaron C-V etch profiler obtained by a donation from colleagues at Lucent Technologies - Bell Laboratories. It is now well past the end of its rated life and needs to be replaced.. The fourth item is the custom Atomika SIMS system which was also donated to us by Bell Labs. The SIMS system is well maintained and operational. The information that would be derived from the $\mathrm{CV}$ etch profiler is complementary to SIMS. SIMS profiles the diffusion of both neutral and active dopants introduced into the material by hydrogenation. Arrangements have been made with TLC Precision Wafer Manufacturing to do any device processing or material regrowth in its microfabrication facilities. The contact person at TLC Precision Wafer Manufacturing is Dr. Timothy T. Childs. As expertise and experience is gained by students and personnel in the processing, it is advantageous to the Center for Microelectronics and Photonics to have these facilities locally. $\mathrm{SiO}_{2}$ deposition for passivation is now facilitated through arrangements with the Microelectronics Center at Georgia Tech.. A stylus profiler and an optical microscope were purchased under a NASA Faculty Award for Research Grant. 


\subsection{Institutional Profile}

Clark Atlanta University (CAU) is a private, coeducational institution of predominantly African American heritage, formed July 1, 1988 by the consolidation of Atlanta University (founded 1865) and Clark College (founded 1869). It is fully accredited by the Southern Association of Colleges and Schools. The University offers undergraduate, graduate and professional degrees, as well as non-degree programs to students of diverse racial, ethnic and socioeconomic backgrounds. CAU is one of only two private historically black comprehensive universities in this country that awards the doctorate degree in three or more disciplines. It is a member of a consortium of historically black colleges and universities called the Atlanta University Center (AUC).

The AUC comprises Clark Atlanta University, the Interdenominational Theological Center, the Morehouse School of Medicine, and three undergraduate colleges: Morehouse (liberal arts college for men), Morris Brown (coeducational four-year college) and Spelman (four-year college for women). The Center has a combined enrollment of over 12,500 students and a combined faculty of over 700. CAU had a Fall 1994 enrollment of 5200 students comprising 4000 undergraduate and 1200 graduate students, and a faculty of about 330 . This consortium affords students many of the opportunities and resources available only in a large university setting, while at the same time providing the nurturing environment characteristic of a small college. Additional opportunities are available to students via the dual degree programs between the Atlanta University Center and the Georgia Institute of Technology and other cooperating institutions (Auburn University, Boston University, North Carolina A\&T State University and Rochester Institute of Technology). This allows students to earn a science or mathematics degree from an AUC institution and an engineering degree from one of these institutions.

\subsection{Bibliography of Literature}

1. S. C. Jain, J. M. McGregor, and D. J. Roulston, J. Appl. Phys. 68, 3748 (1990) and references therein.

2. K. Bergman, Michael Stavola, S. J. Pearton, and J. Lopata, Phys. Rev. B37 , 2770 (1988).

3. N. Pan, B. Lee, S. S. Bose, M. H. Kim, J. S. Hughes, G. E. Stillman, Ken-ichi Arai, and Y. Nashimoto, Appl. Phys. Lett. 50, 1832 (1987).। 
4. G. S. Jackson, N. Pan, M. S. Feng, G. E. Stillman, N. Holonyak, Jr., and R. D. Burnham. Appl. Phys. Lett. 51, 1629 (1987).

5. U. G. Akano, I. V. Mitchell, F. R. Shepherd, C. J. Miner, and R. Rousina, J. Vac. Sci. Technol. A11, 1016 (1993).

6. S. J. Pearton, W. S. Hobson, and C. R. Abernathy, Appl. Phys. Lett. 61, 1588 (1992).

7. "Hydrogen Passivation of the Be Acceptor in p-InP (100)", M. D. Williams, T.H. Chiu, C. A. C. Mendonca, F. G. Storz, M. Chien, and J. Walker, AT\&T Technical Memorandum (unpublished).

8. W. C. Dautremont-Smith, Mat. Res. Soc. Symp. Proc. 104, 313 (1988).

9 J. Chevallier, W. C. Dautremont-Smith, C. W. Tu, and S. J. Pearton, Appl. Phys. Lett. 47, 108 (1985); S. Adachi, and H. Ito, J. Appl. Phys. 64, 2772 (1988).

10. J. M. Zavada, R. G. Wilson, C. R. Abernathy and S. J. Pearton, Appl. Phys. Lett. 64, 2724 (1994).

11. A. Jalil, B. Theys, J. Chevallier, A. M. Huber, C. Grattepain, P. Hirtz, and B. Pajot, Appl. Phys. Lett. 57, 2791 (1990).

12. T. L. Koch, U. Koren, R. P. Gnall, C. A. Burrus, and B. I. Miller, Electronics Lett. 24, 1431 (1988).

13. J. Lopata, W. C. Dautremont-Smith, S. J. Pearton, J. W. Lee, N. T. Ha, and H. S. Luftman, Mat. Res. Soc. Symp. Proc. 163, 501 (1990).

14. J. Weber and M. Singh, Mat. Res. Soc. 104, 325 (1988). 


\title{
10.0 Appendix
}

\section{Michael D. Williams}

\author{
Associate Professor \\ Department of Physics \\ $\&$ \\ Director \\ Center for Microelectronics and Photonics \\ Clark Atlanta University \\ Atlanta, GA 30314
}

\section{Education:}

10/80-1/87 PhD, Stanford University. Physics. Thesis: "The Effect of Charge Transfer on Fermi Level Pinning at the Interface of GaAs (110) Schottky Barriers". Techniques used include angle integrated and constant final state photoemission spectroscopies utilizing line sources and synchrotron facilities, Auger spectroscopy, low energy electron diffraction, I-V characterization, and Kelvin probe measurements of work functions.

10/80-6/81 MS, Stanford University. Physics.

9/74-6/79 BS, Morehouse College. Physics, with honors.

BS, Georgia Institute of Technology. Nuclear Engineering.

\section{Employment:}

12/94-date Associate Professor. Clark Atlanta University, Dept. of Physics, Atlanta, GA. Development of center for microelectronics and photonics. Surface and interface studies of epitaxially grown semiconductor materials.

12/87-12/94 Member of Technical Staff. AT\&T Bell Laboratories, Holmdel, NJ. In situ determination of chemical and electronic properties of multilayer stacks of dissimilar materials during growth by MBE (molecular beam epitaxy) using RHEED (reflection high energy electron diffraction), Auger and photoemission spectroscopies for precise on-line control of parameters essential to bandgap engineering. Ex situ analysis with SIMS (secondary ion mass spectroscopy) to study the diffusion characteristics of dopants and the incorporation of constituent materials with variations in epitaxial growth parameters for systems grown by various techniques. Atomic hydrogen passivation of active carriers in $\mathrm{p}$-InP for device isolation.

9/86-11/87 Visiting Scientist. IBM Alamaden Research Center, San Jose, CA. IR reflection- absorption spectroscopy $\left(4-21 \mathrm{~cm}^{-1}\right)$ of adsorbed species on atomically clean $\mathrm{Pt}(111)$ and measurement of the sticking probabilities of adsorbed species using thermal desorption spectroscopy and molecular beam techniques to ascertain the existence and role of precursor mechanisms in catalytic reactions. 
Additional Member American Physical Society, American Vacuum Society, National Society of Black Physicists, Beta Kappa Chi; national scientific honor society, Sigma Pi Sigma; national physics honor society and Sigma Xi; national scientific research society. 


\section{Michael D. Williams}

\section{Publications:}

1. "Hydrogen Passivation of the Be Acceptor in p-InP (100)", M. D. Williams, J. E. Cunningham, T. H. Chiu, M. Chien, F. G. Storz, and J. A. Walker, Appl. Surf. Sci. 136, 111 (1998).

2. "Space charge spectroscopy of integrated quantum well infrared photodetector-light emitting diode", M. Ershow, B. Yaldiz, A. G. U. Perera, S. G. Matsik, H. C. Liu, M. Cuchanan, Z. R. Wasilewski, M. D. Williams, Infrared Physics and Technology $\underline{42}$, 259 (2001).

3. "Growth and Optical Properties of GaAsSb Quantum Wells for 1.3 um VCSELs", J. E. Cunningham, M. Dinu, J. Shah, F. Quochi, D. Kilper, W. Y. Jan, M. D. Williams, A. Mills, W. E. Henderson, J. Vac. Sci. Technol. B19, 1948 (2001).

4. Characterization of Dopant Passivation by Atomic Hydrogen in Indium Phosphide (100), Walter E. Henderson III, MS Thesis, Clark Atlanta University, Atlanta, Ga, (2004).

5. "UPS study of Hydrogen Complex De-activation in InP (100): Zn", M. D. Williams, S.C. Williams, S.A. Yasharahla, and N. Jallow, accepted for publication in Applied Surface Science (2006)

Submitted Manuscripts:

1. " Liquid Nitrogen Cryostat for the Financially Challenged: A Poor Man's Cryostat ", A. Gyekye (student), M. D. Williams, Thomas Huser and Anthony Esposito. submitted for publication in J.Vac. Sci. Technol. A

Manuscripts in Progress:

A. "Work Function Variation of AlN Epilayers with Substrate Temperature", M. D. Williams, for submission to J. Vac. Sci. Technol. A.

\section{Talks:}

1. Walter Henderson (Graduate Student) - "A Thermodynamic Description of Impurity Passivation by Atomic Hydrogen in Indium Phosphide", Departmental Seminar, Dept. of Physics, Clark Atlanta University, Atlanta, Ga, 5/5/99 (Contributed). 
2. M. D. Williams - "Growth and Characterization of III-V Semiconductors for Device Applications", Program in Physical Sciences seminar, Spelman College, Atlanta, Ga., 7/19/99 (Invited).

3. Walter E. Henderson (Graduate Student) - "Characterization of Hydrogen Passivation in p-type InP (100)", 46th International Symposium of the American Vacuum Society, Seattle, Wa, 10/ 24 - 29/99 (Contributed)

4. M. D. Williams - "Free Standing Quantum Wells", Dept. of Physics and Astronomy colloquium, Georgia State University, Atlanta, Ga., 3/30/00 (Invited).

5. M. D. Williams - Graduate Breakout Session (Co-Moderator): "Expectations of Graduate School" and "The End is Near, Now What? The Job Market". 14th Annual National Conference of Black Physics Students, North Carolina A \& T State University, Greensboro, NC., 3/16-19/00 (Invited).

6. Walter E. Henderson (Graduate Student) - "Experimental Methods for the Study of Hydrogen Passivation of (100) InP", Dept. of Physics seminar, Clark Atlanta University, Atlanta, Ga., 4/13/00 (Contributed).

7. J. E. Cunningham - "Growth and Optical Properties of GaAsSb Quantum Wells for 1.3 um VCSELs", J. E. Cunningham, M. Dinu, J. Shah, F. Quochi, D. Kilper, W. Y. Jan, M. D. Williams, A. Mills, W. E. Henderson, 19 ${ }^{\text {th }}$ North American Conference on Molecular Beam Epitaxy, Tempe, AZ, 10/16-18/2000 (Contributed).

8. Walter E. Henderson (Graduate Student) - "Characterization of Dopant Passivation in Hydrogenated InP (100)", 2000 Meeting of the Southeastern Section of American Physical Society, Mississippi State University, Starkville, MS, 11/2-4/2000. (Contributed).

9. M. D. Williams, "Growth and Characterization of III-V Semiconductors for Device Applications", Dept. of Chemistry seminar, City College of the City Univ. of New York, New York, NY., 11/8/2000 (Invited).

10. Shala Mance (Graduate Student) - "Small Spot Photoluminescence for Nanostructure Characterization of III-V Semiconductors", Dept. of Physics seminar, Clark Atlanta University, Atlanta, GA, 12/6/2001 (Contributed).

11. M. D. Williams, "Nanostructure Technology Infrastructure Development", $25^{\text {th }}$ Conference of the National Society of Black Physicist's, , Huntsville, AL, 3/1316/2002 (Invited).

12. Sharah Yasharahla (Graduate Student) - "Hydrogen Passivation in InP (100)", Dept. of Physics seminar, Clark Atlanta University, Atlanta, GA, 3/6/2003 (Contributed). 
13. Adwoa Gyekye (Graduate Student) - "Interaction of Quantum Confined Excitonic States with Surface States in III-V Semiconductors", Dept. of Physics seminar, Clark Atlanta University, Atlanta, GA, 4/17/2003 (Contributed).

14. Sharah Yasharahla (Graduate Student) - "Dopant Neutralization of Hydrogenated InP", Dept. of Physics seminar, Clark Atlanta University, Atlanta, GA, 11/20/2003 (Contributed).

15. M. D. Williams - (Panelist): “Activities of the American Physical Society's Committee on Minorities in Physics", Special Session - Committee on the Status of Minorities in Astronomy, 203rd Meeting of the American Astronomical Society, Atlanta, GA, 1/4-8/2004 (Invited).

16. M. D. Williams - (Panelist): "Electron Beam Lithography \& Applications", Georgia Tech Microelectronics Research Center Electron Beam Lithography Workshop, Atlanta, GA, 08/13/2004 (Invited).

17. M. D. Williams - "Characterization of Hydrogen Complex Formation in InP:Zn (100)", AVS 51st International Symposium, Anaheim, CA, 11/ 14 - 19/2004 (Contributed). 